\title{
CONSTRUYENDO EL PRINCIPIO DE RESPONSABILIDAD DE PROTEGER PARA FORTALECER LA SEGURIDAD CLIMÁTICA
}

\author{
CONSTRUCTING THE PRINCIPLE OF REPONSABILITY TO PROTECT TO \\ STRENGTHE CLIMATE SECURITY
}

Susana Borràs

Profesora Contratada Doctora de Derecho Internacional y Relaciones Internacionales. Investigadora del Centro de Estudios de Derecho Ambiental de Tarragona (CEDAT), Universidad Rovira i Virgili. Tarragona (España).

Convidada

Doi: $10.5585 /$ rdb.v13i6.352

\begin{abstract}
RESUMEN: El cambio climático constituye, hoy por hoy, una grave amenaza para la seguridad internacional, especialmente para aquéllos países más vulnerables a sus efectos. Los acontecimientos climáticos extremos han aumentado en frecuencia y gravedad en los últimos años y plantean cuestiones fundamentales con respecto a la idoneidad del régimen internacional actual en materia de asistencia humanitaria a las víctimas de los desastres naturales. El presente artículo analiza como la seguridad climática se debe construir mediante la asunción de la responsabilidad del propio Estado de proteger a su población de los riesgos, amenazas y desastres climáticos, consintiendo la asistencia internacional. Pero también, la responsabilidad de los demás Estados de mitigar el cambio climático basándose en la mejor información científica disponible y de acuerdo con su contribución histórica al cambio climático para garantizar que todas las personas puedan adaptarse a los efectos adversos del cambio climático y garantizar la protección de sus derechos humanos. A pesar de la gran envergadura e impacto de los desastres climáticos, el Derecho internacional que regula las actividades relacionadas con la ayuda humanitaria y protección de las víctimas en estas situaciones está muy poco desarrollado. El vacío normativo existente se debe, en cierto modo, a la consideración de estos fenómenos como naturalmente inevitables, pero que terminan siendo auténticas catástrofes cuando la gestión del desastre fracasa. De ahí, la pertinencia de trasladar la doctrina de la "responsabilidad de proteger" (R2P) para asegurar la protección de las víctimas de desastres climáticos por parte de la comunidad internacional.
\end{abstract}

Palabras clave: Responsabilidad de proteger; Cambio climático; Seguridad climática; Desastres climáticos; Emergencia humanitaria.

ABSTRACT: Climate change is, today, a serious threat to international security, especially for those most vulnerable to its impacts. Extreme weather events have increased in frequency and severity in recent years and raise fundamental questions regarding the appropriateness of the current international regime on humanitarian assistance to victims of natural disasters. This article analyzes how climate security must be built by taking on the responsibility of States to protect their populations from the risks, threats and climate disasters, international assistance consenting 
own. But also the responsibility of all States to mitigate climate change based on the best scientific information available and in accordance with its historical contribution to climate change to ensure that all people can adapt to the adverse effects of climate change and ensure protection of their human rights.Despite the enormity and impact of climate disasters, international law regulating the activities related to humanitarian assistance and protection of victims in these situations is very underdeveloped. The existing regulatory gap is, in a way, to the consideration of these phenomena as naturally inevitable, but they end up being authentic when disaster management fails. Hence, the relevance of shifting the doctrine of "responsibility to protect" (R2P) to ensure the protection of victims of climate disasters by the international community.

Keywords: Responsibility to protect; Climate change; Climate security; Climate desarters; Humanitarian emergency.

Sumário: Introducción; 1 . Una nueva amenaza a la seguridad humana: el cambio climático; 2. La doctrina R2P: evolución y perspectivas; 3. La extensión de la R2P al ámbito de la garantía de la seguridad climática; 4. La "soberanía como responsabilidad" como fundamento jurídico de la R2P; Reflexiones finales: de la intervención humanitaria a la R2P; Referencias bibliográficas.

\section{INTRODUCCIÓN}

El cambio climático constituye, hoy por hoy, una grave amenaza para la seguridad internacional, especialmente para aquéllos países más vulnerables a sus efectos. El Cuarto Informe del Grupo Intergubernamental de Expertos sobre Cambio Climático (IPCC) ya afirmaba, con una rotundidad del 90\%, que el cambio climático es consecuencia de la actividad humana, prediciendo incrementos en el promedio de la temperatura del aire y del océano, el deshielo, el incremento del nivel del mar a nivel mundial. Las proyecciones indican cambios de temperatura a finales del s. XXI, respecto finales del s. XX, que pueden oscilar en un rango entre 1,8 y 4 grados centígrados. Por encima de los 2 grados muchos impactos serán irreversibles en el medio ambiente y los ecosistemas: el agua potable y los alimentos escasearán; desaparecerán muchas especies animales y vegetales; muchas tierras dejarán de ser cultivables; se alterará gravemente del perfil de las costas; aumentará la difusión de enfermedades infecciosas, los desastres naturales serán más frecuentes, aumentarán los índices de mortalidad debido a inundaciones, tormentas, sequías y olas de calor, etc. Estos acontecimientos climáticos extremos han aumentado en frecuencia y gravedad y plantean cuestiones fundamentales con respecto a la idoneidad del régimen internacional actual en materia de asistencia humanitaria a las víctimas de los desastres naturales. En la actualidad, no existe un tratado multilateral equivalente a los Convenios de Ginebra de $1949^{1}$ — que se aplican a las víctimas de los conflictos armados_- en el que se estipule el derecho de las víctimas de los desastres naturales a recibir ayuda humanitaria ${ }^{2}$.

\footnotetext{
${ }^{1}$ En particular, el IV Convenio de Ginebra del 12 de agosto de 1949 relativo a la protección debida a las personas civiles en tiempo de guerra.

${ }^{2}$ En 1984, la Oficina del Coordinador de las Naciones Unidas para el Socorro en Casos de Desastre (ONUSCD) intentó trazar un proyecto de convenio sobre la asistencia de urgencia. En el preámbulo del proyecto de convenio se dice que «la comunidad internacional ha prestado asistencia de manera voluntaria en casos concretos de desastre, y sigue prestándola cuando es necesario». Vid. el proyecto de convenio de la ONU para facilitar la asistencia de urgencia, art. 1, inciso. 1c), Doc. de la ONU A/39/267/Add.2, 1984. También consultar «Strengthening the Revista de Direito Brasileira | São Paulo, SP | v. 13 | n. 6 | p. 39 - 60 | jan./abr. 2016
} 
Tampoco la Convención de 1951 sobre el Estatuto de los Refugiados protege a las personas que se ven desplazadas a través de las fronteras debido a los desastres naturales y a los efectos del cambio climático.

Los efectos adversos del cambio climático provocado por el ser humano interfieren en el disfrute de los derechos humanos, en particular de los derechos económicos, sociales y culturales, y, por lo tanto, amenazan el desarrollo, la estabilidad, la paz y la seguridad en los planos nacional e internacional. La alteración brusca del sistema climático y la desprotección legal a la que se enfrentan sus víctimas pone de manifiesto que la concepción de la seguridad humana transciende a los intereses nacionales de los Estados y se supedita a las necesidades de sus poblaciones, añadiendo otra dimensión, la seguridad climática, como aquélla que debe prevenir a las poblaciones de los riesgos y amenazas que genera el cambio climático.

Por consiguiente, la seguridad climática se debe construir mediante la asunción de la responsabilidad del propio Estado de proteger a su población de los riesgos, amenazas y desastres climáticos, consintiendo la asistencia internacional. Pero también, la responsabilidad de los demás Estados de mitigar el cambio climático basándose en la mejor información científica disponible y de acuerdo con su contribución histórica al cambio climático para garantizar que todas las personas puedan adaptarse a los efectos adversos del cambio climático y garantizar la protección de sus derechos humanos. En efecto, la exposición a los efectos radicales del cambio climático no puede ser analizada sin determinar las responsabilidades de los grandes emisores de gases de efecto invernadero en su contribución a generar este problema global: la mayor o menor contribución histórica debe determinar, de acuerdo con el principio de responsabilidades comunes, pero diferenciadas, un mayor nivel de responsabilidad y compromiso, no solo respecto a la mitigación, sino también respecto a la asistencia a aquellos Estados más vulnerables que ya sufren las consecuencias del cambio climático.

Tal y como menciona el preámbulo de la Convención Marco de las Naciones Unidas sobre el Cambio Climático (CMNUCC), "la naturaleza mundial del cambio climático requiere la cooperación más amplia posible de todos los países y su participación en una respuesta internacional efectiva y apropiada, de conformidad con sus responsabilidades comunes pero diferenciadas y sus capacidades respectivas y sus condiciones sociales y económicas" ${ }^{3}$.

La responsabilidad, que incumbe a los principales emisores de gases de efecto invernadero, debería incluir la acción de protección ante eventuales emergencias humanitarias surgidas como consecuencia de los efectos del cambio climático, que azotan a los países más vulnerables, los cuales son incapaces de proferir protección a su propia población. Es en esta situación en la que se plantea la posible aplicación de la doctrina de la "Responsabilidad de Proteger" (R2P, por su acrónimo en inglés), según la cual los Estados soberanos tienen la obligación de defender a su población del genocidio y otras atrocidades masivas pero, cuando no pueden o no quieren hacerlo, también entra en juego la responsabilidad del conjunto de Estados del mundo.

No obstante, la doctrina R2P es una cuestión ciertamente novedosa en el ámbito del Derecho internacional y que todavía no encuentra unanimidad en la doctrina. Esto, sin duda dificulta una posible ampliación del principio para hacer frente a las crisis humanitarias emergentes, como aquéllas surgidas de los desastres climáticos.

coordination of humanitarian emergency assistance of the UN», Resolución 46/182 de la Asamblea General de la ONU del 19 de diciembre de 1991.

${ }^{3}$ BOE de 1 de febrero de 1994.

Revista de Direito Brasileira | São Paulo, SP | v. 13 | n. 6 | p. 39 - 60 | jan./abr. 2016 
Esta no es una cuestión baladí, sobre todo si se tiene en cuenta que los desastres climáticos, tales como terremotos, huracanes, sequías o inundaciones entre otros, afectan a unos 250 millones de personas cada año. Los tsunamis, huracanes y terremotos que azotaron partes de Asia y las Américas en 2004 y 2005 acentuaron la necesidad de prestar atención a los múltiples desafíos en materia de derechos humanos que enfrentan las personas afectadas por estos desastres. Además los pronósticos no son muy alentadores, para los próximos años se estima que el número de desastres climáticos podría crecer hasta en un 50\% generando 375 millones de víctimas anuales.

A pesar de la gran envergadura e impacto de algunos de estos desastres, el Derecho internacional que regula las actividades relacionadas con la ayuda humanitaria y protección de las víctimas en estas situaciones está muy poco desarrollado ${ }^{4}$. El vacío normativo existente se debe, en cierto modo, a la consideración de estos fenómenos como naturalmente inevitables, que se convierten en autenticas catástrofes cuando la gestión del desastre fracasa. Esta realidad no deja de ser preocupante si se tiene en cuenta que los desastres naturales afectan con mayor severidad y frecuencia en los países menos desarrollados, ya que cuentan con menos recursos y capacidad para hacer frente a estas situaciones. Es en este contexto que se plantea una intervención efectiva de la comunidad internacional, con el fin de atenuar los efectos y proteger a las víctimas desatendidas por la incapacidad de las autoridades locales.

La ayuda internacional es primordial para brindar asistencia a las víctimas de los desastres en aquellas situaciones en las que el Estado afectado no cuenta con los mecanismos, capacitación o recursos necesarios para hacer efectiva una respuesta adecuada, o en los casos en que la magnitud del impacto del evento es tal, que es necesario que los mecanismos de respuesta de las autoridades locales se vean reforzadas con la llegada de ayuda externa.

La incapacidad de los Gobiernos para prestar ayuda o solicitar asistencia exterior con prontitud ha provocado, sin duda, muy graves sufrimientos. Por consiguiente, se hace necesaria la aplicación de la R2P en estas situaciones, permitiría llenar el vacío entre legalidad y legitimidad en las intervenciones de la comunidad internacional con el objetivo de proteger los derechos humanos en circunstancias extremas.

El presente artículo analiza precisamente la posibilidad de ampliar esta doctrina para dar cabida a situaciones tales, como son las producidas por el cambio climático, que constituyen una amenaza real, que comprometen la seguridad humana de las poblaciones más vulnerables del mundo y que exigen la intervención proteccionista de los Estados, especialmente de aquéllos, que más responsabilidades se les atribuye por haber contribuido al fenómeno del cambio climático.

\section{UNA NUEVA AMENAZA A LA SEGURIDAD HUMANA: EL CAMBIO CLIMÁTICO}

En 1987 la Comisión Mundial del Medioambiente y del Desarrollo afirmó que era necesario "ampliar la noción de seguridad de forma que, además de las amenazas políticas y militares a la soberanía nacional, también se incluyera la incidencia creciente de los atentados al medioambiente en el ámbito local, nacional, regional y mundial". Entre estos nuevos desafíos que

\footnotetext{
${ }^{4}$ Según la Corte Internacional de Justicia, la ayuda humanitaria permitida durante los conflictos armados se define como «el suministro de alimentos, ropa, medicamentos y otra asistencia humanitaria, y no incluye el abastecimiento de armas, sistemas de armas, municiones, u otros equipos, vehículos, o materiales que puedan usarse para provocar lesiones graves o la muerte». Vid. Military and paramilitary Activities in and against Nicaragua (Merits), Judgment, ICJ Rep., 1986, pp. 157 y 125. Pese a que esta declaración se formuló en el marco de un conflicto armado, en principio no hay objeciones para su aplicación en caso de desastre natural.
}

Revista de Direito Brasileira | São Paulo, SP | v. 13 | n. 6 | p. 39 - 60 | jan./abr. 2016 
cuestionan la seguridad humana está el del cambio climático. En efecto, el fenómeno del cambio climático se presenta en la actualidad como uno de los desafíos más importantes a los que se enfrenta la comunidad internacional en su conjunto.

De esta manera, en 1994 se asienta un nuevo concepto de seguridad internacional, el de seguridad humana, a través del Informe del Programa de Naciones Unidas para el Desarrollo Humano (PNUD), en el que además se estableció el principal indicador del Índice de Desarrollo Humano (IDH). Entones, la seguridad humana se concibe desde dos vertientes: seguridad contra amenazas crónicas, tales como el hambre, la enfermedad o la represión. Y seguridad como protección contra alteraciones súbitas y dolorosas de la vida cotidiana.

A partir de entonces, la noción de seguridad se centra en el bienestar del ser humano y se clasifica en siete, las posibles amenazas contra la seguridad: la seguridad económica, la seguridad alimentaria, la seguridad en materia de salud, la seguridad ambiental, la seguridad personal, la seguridad de la comunidad y la seguridad política.

El PNUD añadía a este concepto que "La pérdida de la seguridad humana puede ser un proceso lento y silencioso o una emergencia abrupta y estridente. Puede ser obra humana, como resultado de opciones erradas de política. Puede ser consecuencia de las fuerzas de la naturaleza. O puede ser una combinación de ambos casos, como ocurre con frecuencia cuando el deterioro del medio ambiente desemboca en un desastre natural, seguido de la tragedia humana"5.

Con esta nueva concepción de seguridad, se ponía de manifiesto la gran panoplia de amenazas a las cuales se podía enfrentar la Humanidad. Así lo constataba Kofi Annan, en su informe titulado Nosotros los pueblos, pronunciado ante la Asamblea General de la Organización de las Naciones Unidas (ONU), «La seguridad no puede ser definida solo como la ausencia de conflicto armado, ya sea dentro del Estado o entre diferentes Estados. Los abusos de los derechos humanos, los desplazamientos de la población civil, el terrorismo internacional, la pandemia del SIDA, el tráfico de armas, de drogas y de personas, los desastres medioambientales, representan una amenaza directa a la seguridad humana, forzándonos a adoptar una estrategia coordinada» ${ }^{6}$

Por lo tanto, se puede afirmar que el cambio climático y sus consecuencias constituyen una de las amenazas contra la seguridad humana, en cuanto puede ser generador de grandes desastres naturales y humanitarios. Así, por ejemplo, la organización no gubernamental (ONG) Alert International ha identificado 46 países con un elevado riesgo de conflicto armado debido al cambio climático y 56 Estados amenazados de inestabilidad política ${ }^{7}$. Según el Relator Especial sobre el derecho a la alimentación, la degradación de las tierras ha provocado, junto con otros factores, enfrentamientos por los recursos en el conflicto de la región de Darfur del Sudán y en otros conflictos en África ${ }^{8}$. En este sentido, no sólo los desastres naturales inducidos por el cambio climático, con un impacto sobrevenido e inminente, son el foco de emergencias humanitarias (tsunamis, terremotos, tornados, huracanes, tifones,...), sino también el deterioro progresivo de los recursos naturales por la escasez de agua, por ejemplo, conducen a una amenaza a la seguridad humana y a un riesgo real y/o potencial de conflictividad.

\footnotetext{
${ }^{5}$ PNUD, Informe sobre Desarrollo Humano de 1994, p. 26.

${ }^{6}$ Vid. ANNAN, K., Informe del Milenio Naciones Unidas. New York, 2000.

${ }^{7}$ Puede encontrarse información sobre los indicadores y criterios utilizados para la evaluación de los países en "A climate of conflict: the links between climate change, peace and war", International Alert, noviembre de 2007, págs. 18 y $19, \quad$ disponible en www.international-alert.org/pdf/A_Climate_ Of_Conflict.pdf.

${ }^{8}$ Consultar Doc. A/HRC/7/5.
} Revista de Direito Brasileira | São Paulo, SP | v. 13 | n. 6 | p. 39 - 60 | jan./abr. 2016 
Además, los problemas que a menudo enfrentan las personas afectadas por las consecuencias de los desastres naturales incluyen: acceso desigual a la asistencia; discriminación en la prestación de asistencia; reubicación forzosa; violencia sexual y por motivos de género; pérdida de documentación; reclutamiento de niños en las fuerzas combatientes; regreso o reasentamiento peligroso o involuntario; y cuestiones relacionadas con la restitución de la propiedad. Las poblaciones afectadas se ven muy a menudo forzadas a abandonar sus hogares o lugares de residencia debido a la destrucción de sus casas y viviendas por erupciones volcánicas, tsunamis, inundaciones, sequía, deslizamientos de tierra, terremotos y tornados. Por consiguiente, una gran cantidad de personas son internamente desplazadas debido a estos desastres o por el temor a futuros daños.

Ante los riesgos y las consecuencias que supone el cambio climático, en 2008 el Consejo de Derechos Humanos, en su Resolución 7/23, pidió a la Oficina del Alto Comisionado de las Naciones Unidas para los Derechos Humanos (ACNUDH) que realizara un estudio sobre los derechos humanos y el cambio climático. El estudio ${ }^{9}$ se presentó en 2009 y abordaba, entre otras cosas, las consecuencias de los desplazamientos y los conflictos inducidos por el cambio climático. También analizaba las consecuencias del cambio climático en las obligaciones pertinentes con arreglo a la normativa internacional de derechos humanos.

Un año después, el Secretario General ONU, a través de un informe titulado "Cambio Climático y sus posibles implicaciones en materia de seguridad" señalaba que el cambio climático es una amenaza para los derechos humanos y para el desarrollo económico; produce tensiones y conflictos por los recursos; puede poner en peligro las bases de la existencia del Estado; y su efectos pueden provocar cambios en la disponibilidad y acceso a los recursos naturales.

También la Resolución 63/281 de la Asamblea General de la ONU establecía que "la naturaleza mundial del cambio climático requiere la cooperación más amplia posible de todos los países y su participación en una respuesta internacional efectiva y apropiada, de conformidad con sus responsabilidades comunes pero diferenciadas, sus capacidades respectivas y sus condiciones sociales y económicas"10. También señalaba que el cambio climático es una amenaza para los derechos humanos y para el desarrollo económico, que produce tensiones y conflictos por los recursos, y que puede poner en peligro una de las bases de la existencia del Estado, como el territorio estable, y en algunos casos su propia supervivencia.

En el informe de 2009 que marcó la ruta de los derechos humanos y el cambio climático, la Oficina del Alto Comisionado de las Naciones Unidas para los Derechos Humanos (OACDH) concluyó que el cambio climático amenaza el disfrute de un amplio rango de derechos humanos. La OACDH describió las obligaciones en materia de derechos humanos como aquellas que proveen "importante protección a las personas cuyos derechos se ven afectados por el cambio climático" " y enfatizó en particular las obligaciones del Estado de protegerlos más allá de sus propias fronteras y a cooperar internacionalmente con respecto al cambio climático ${ }^{12}$.

\footnotetext{
${ }^{9}$ Consultar Doc. A/HRC/10/61.

${ }^{10}$ Resolución aprobada por la Asamblea General el 3 de junio de 2009, nº $.63 / 281$. El cambio climático y sus posibles repercusiones para la seguridad, Doc. A/RES/63/281, de 11 de junio de 2009. Disponible en línea en: http://www.un.org/en/ga/search/view_doc.asp?symbol=A/RES/63/281\&Lang=S (recuperada el 3 de abril 2014).

${ }^{11}$ Oficina del Alto Comisionado para los Derechos Humanos de las Naciones Unidas (OACDH). Informe de la Oficina del Alto Comisionado de las Naciones Unidas para los Derechos Humanos sobre la relación entre el cambio climático y los derechos, para.71. U.N. Doc. A/HRC/ (2009) [en adelante Informe OACDH].

${ }^{12}$ Ibíd., párrs. 84-89.
}

Revista de Direito Brasileira | São Paulo, SP | v. 13 | n. 6 | p. 39 - 60 | jan./abr. 2016 
Asimismo, en la elaboración de los Acuerdos de Cancún que surgió de la $16^{\text {a }}$ Conferencia de las Partes (COP16) ante la Convención Marco de las Naciones Unidas sobre Cambio Climático (CMNUCC), los países tomaron nota de cómo el cambio climático tendrá un conjunto de implicaciones directas e indirectas para el disfrute efectivo de los derechos humanos ${ }^{13}$

En el marco de la Unión Europea, en 2008, el entonces Alto representante,Javier Solana y la Comisión Europea presentaron al Consejo Europeo el Informe sobre "Cambio climático y seguridad internacional", que se centra en su impacto en la seguridad internacional y considera los efectos de estas consecuencias para la propia seguridad de Europa y cómo debería responder la Unión. El informe afirma que los efectos del cambio climático se están sintiendo ya, y describe algunas de las formas de amenazas impulsadas por éste que pueden ocurrir en diferentes regiones del mundo, entre las que menciona los conflictos por recursos, el daño económico y el riesgo para las ciudades costeras y las infraestructuras críticas, la pérdida de territorios y las disputas fronterizas, la migración inducida por el medio ambiente, las situaciones de fragilidad y radicalización, la tensión en el suministro de energía y la presión sobre la gobernanza internacional. El informe recomienda como líneas estratégicas de acción el aumento de las capacidades de la UE, un liderazgo multilateral de la UE para promover la seguridad climática mundial y la cooperación con terceros países ${ }^{14}$.

En este contexto, la constatación de la implicación del cambio climático con la protección y garantía de los derechos humanos es incuestionable, en la medida que compromete la seguridad humana en todas sus dimensiones y constituye una amenaza incluso para la paz internacional.

\section{LA DOCTRINA R2P: EVOLUCIÓN Y PERSPECTIVAS}

El concepto de seguridad humana está íntimamente relacionado con un deber que tienen los Estados: el de proteger a sus ciudadanos ante determinadas situaciones de gravedad, obligación que a su vez conlleva el surgimiento de un derecho de injerencia a favor de la comunidad internacional, bajo mandato del Consejo de Seguridad de Naciones Unidas, en caso que ese deber no sea cumplido. Esta correlación entre deber y derecho de injerencia ha sido, en cierto modo consensuado a nivel internacional, en los casos en los que la población se encuentra expuesta a genocidio, crímenes de guerra, depuración étnica y crímenes de lesa humanidad. En el caso de los riesgos que plantea el cambio climático para la seguridad humana, es necesario analizar la posible aplicación de este deber/derecho, pero no sin antes analizar, con mayor profundidad, el concepto de R2P.

Una de las primeras veces en que se utiliza este concepto es tras el Informe del Milenio, en 2001, cuando la Comisión Internacional sobre Intervención y Soberanía de los Estados (ICISS, por sus siglas en inglés), establecida por el Gobierno del Canadá, publicó un informe

\footnotetext{
${ }^{13}$ Vid. $6{ }^{a}$ Conferencia de las Partes de la Convención Marco de Naciones Unidas sobre el Cambio Climático. Acuerdos de Cancún: resultado de la labor del Grupo de Trabajo Especial sobre la cooperación a largo plazo en el marco de la Convención. Decisión 1/CP16. UN Doc. FCCC/CP/2001/13 (11 de marzo de 2011) [en adelante Los Acuerdos de Cancún] disponible en http://unfccc.int/resource/docs/2010/cop16/spa/07a01s.pdf\#page=2.

${ }^{14} \mathrm{El}$ informe señala que un incremento de la temperatura media de la atmósfera por encima del umbral de seguridad identificado por la comunidad científica ( $2 \mathrm{C}^{\mathrm{o}}$ sobre la temperatura existente en los tiempos preindustriales), conducirá a numerosos conflictos derivados de los impactos económicos, políticos, ambientales y sociales producidos por la alteración del clima. Disponible http://www.consilium.europa.eu/uedocs/cms_data/docs/pressdata/en/reports/99387.pdf (recuperado el 3 de marzo 2014).
}

Revista de Direito Brasileira | São Paulo, SP | v. 13 | n. 6 | p. 39 - 60 | jan./abr. 2016 
titulado "La responsabilidad de proteger"15. La ICISS reformuló el discurso y abandonó la idea del derecho de terceros a intervenir para adoptar el término de la responsabilidad (ante todo, la del Estado en cuestión, de ofrecer protección a sus propios ciudadanos). La responsabilidad de proteger incluía un extenso paquete de medidas, que implicaban no sólo reaccionar para proteger a la población de daños graves, sino también prevenir dichas situaciones y reconstruir tras su incidencia. En dicho informe se estableció que la soberanía no solamente daba al Estado el derecho de "controlar" sus asuntos, sino que también confería al Estado la "responsabilidad" primaria de proteger a la población dentro de sus fronteras. En él se proponía que cuando un Estado no protegiera a su población, ya fuera por falta de capacidad o de voluntad, la responsabilidad incumbía a la comunidad internacional en su conjunto.

A diferencia de la noción de seguridad humana que pretende la creación de las condiciones que eviten situaciones de inseguridad a los seres humanos, se considera que la R2P tiene como sus aspectos principales los de prevenir, reaccionar y reconstruir. En efecto, en el informe de la Comisión se establecía que el concepto de la responsabilidad de proteger incluía una serie de obligaciones: en primer lugar, la responsabilidad de prevenir que se cometan crímenes de esa naturaleza; en segundo lugar, la responsabilidad de reaccionar cuando ocurran y finalmente, la responsabilidad de reconstruir las sociedades luego de una crisis.

El Secretario General de las Naciones Unidas, Koffi Annan, en la sesión inaugural del quincuagésimo octavo periodo de sesiones de la Asamblea General (septiembre de 2003) anunció su intención de crear un Grupo de Alto Nivel sobre las Amenazas, los Desafíos y el Cambio. Meses después informó al presidente de la Asamblea General de la ONU la creación de dicho grupo. El Grupo de Alto Nivel tenía el siguiente mandato: a) Examinará las amenazas en el mundo de hoy y hará un análisis de los futuros desafíos a la paz y la seguridad internacionales. Por más que pueda seguir habiendo distintas ideas acerca de la importancia relativa de las diversas amenazas a que hace frente un determinado Estado miembro, es importante encontrar un equilibrio adecuado en el plano mundial y también es importante entender las conexiones que hay entre distintas amenazas; b) Indicará claramente la contribución que puede hacer la acción colectiva para superar esos problemas; c) Recomendará los cambios necesarios para asegurar una acción colectiva eficaz procediendo, entre otras cosas, a un estudio de los principales órganos de las Naciones Unidas.

El informe "Un Mundo más Seguro: la Responsabilidad que Compartimos"16, del Grupo de Alto Nivel sobre las amenazas, los desafíos y el cambio (diciembre de 2004) se divide en cuatro partes, en varias de las cuales asume la posición tomada por el ICISS en relación a la "responsabilidad de proteger".

La primera parte de este informe, titulada "Hacia un nuevo consenso en materia de seguridad" se explica que: al suscribir la Carta de las Naciones Unidas, los Estados no sólo se benefician de los privilegios de la soberanía, sino también asumen sus responsabilidades. Cualesquiera hayan sido las percepciones prevalecientes cuando el concepto de la soberanía estatal surgió tras la Paz de Westfalia, actualmente dicho concepto conlleva claramente la

\footnotetext{
${ }^{15}$ Para consultar el informe en español: cfr. http://www.ca/pdf/Spanish-report.pdf. Según los analistas, la R2P tiene sus antecedentes en el documento "Una Agenda para la paz" del entonces Secretario General de la ONU B. B. Ghali, con sus ideas de democracia preventiva, peacemaking, peacekeeping y construcción de la paz posconflicto. Al respecto, consultar MURITHI, T., "The African Union's transition from non-intervention to non-indifference: an ad hoc approach to the Responsibility to Protect?" International Politics and Society, núm. 1, 2009, p. 91.

${ }^{16}$ UN. Doc. A/59/565, "Un mundo más seguro: la responsabilidad que compartimos", Informe del Grupo de Alto Nivel sobre las Amenazas, los Desafíos y el Cambio, Quincuagésimo Noveno Periodo de Sesiones, tema 55: Seguimiento de los Resultados de la Cumbre del Milenio, 2 de diciembre de 2004, anexo II, párr. 2 del mandato, p. 104. Puede ser consultado en castellano en: http://www.un.org/spanish/secureworld/
}

Revista de Direito Brasileira | São Paulo, SP | v. 13 | n. 6 | p. 39 - 60 | jan./abr. 2016 
obligación de los Estados de proteger el bienestar de su población y de cumplir sus obligaciones con la comunidad internacional en general.

No obstante, no puede darse por sentado que todos los Estados podrán o querrán siempre cumplir las obligaciones que les incumben en relación con su propia población y no causar daño a sus vecinos. Y en tales circunstancias los principios de la seguridad colectiva significan que parte de esa obligación debe ser asumida por la comunidad internacional, actuando de conformidad con la Carta de las Naciones Unidas y la Declaración Universal de Derechos Humanos para crear la capacidad o proporcionar la protección necesaria, según el caso.

Para el Grupo de Alto Nivel los Estados deben asumir su soberanía con responsabilidad, no sólo basándose en la autonomía (soberanía interna), sino también en la protección de su propia población y la de todos los Estados en general, de conformidad con la Carta de las Naciones Unidas y la Declaración Universal de Derechos Humanos. Sin embargo, algunos Estados no tienen la capacidad como para poder asumir su soberanía de manera responsable, por lo que según el informe, "para quienes estén en condiciones de ayudar a otros a mejorar esa capacidad, esta tarea debe ser parte de su responsabilidad", lo que conllevaría a mejorar la efícacia de un sistema de seguridad colectiva digno de crédito.

En la segunda parte del informe, el grupo hizo un análisis de las amenazas y peligros a la paz y seguridad internacionales, incluidas aquellas que no podrían ser solucionadas con el mero uso de la fuerza. El grupo advirtió además que "cualquier suceso o proceso que cause muertes a gran escala o una reducción masiva en las oportunidades de vida y que socave el papel del Estado como unidad básica del sistema internacional constituye una amenaza a la seguridad internacional". En ese sentido, se dividió en seis grupos las amenazas que deben preocupar al mundo: Las amenazas económicas y sociales, como la pobreza, las enfermedades infecciosas y la degradación ambiental; Los conflictos entre Estados; Los conflictos internos, como la guerra civil, el genocidio y otras atrocidades a gran escala. Las armas nucleares, radiológicas, químicas y biológicas. El terrorismo. La delincuencia organizada transnacional. Finalizando la segunda parte, el grupo analiza el papel de las sanciones, advirtiendo que éstas son una herramienta vital, aunque imperfecta, para hacer frente preventivamente a las amenazas a la paz y la seguridad internacionales.

La doctrina R2P fue reafirmada en el Informe del Secretario General de Naciones Unidas, denominado "Un concepto más amplio de libertad: desarrollo, seguridad y derechos humanos para todos", de marzo de 2005, en relación a la aplicación de los resultados de la Cumbre del Milenio y como documento para la preparación de la Cumbre Mundial de 2005. En este informe, el secretario general hace suyas las recomendaciones presentadas en el informe del Grupo de Alto Nivel sobre las Amenazas, los Desafíos y el Cambio, sin embargo matiza o reforma algunas.

En la introducción del informe, titulada "2005, Una oportunidad histórica", el secretario general expresa que, aprovechando la Cumbre Mundial 2005, que examinará los progresos realizados desde que se proclamó la Declaración del Milenio de las Naciones Unidas y que los dirigentes mundiales pueden tomar decisiones que conlleven a: reducir a la mitad la pobreza en el mundo y frenar la propagación de las principales enfermedades conocidas, reducir la prevalencia de los conflictos violentos y del terrorismo; fortalecer el respeto de la dignidad humana en todos los países; y crear instituciones internacionales más modernas para ayudar a la humanidad a alcanzar esos nobles objetivos. Finalmente, se refiere a que"Actuando con audacia - y actuando juntos- podemos hacer que en todas partes los seres humanos estén más seguros, sean más prósperos y tengan mejores posibilidades de gozar de sus derechos humanos fundamentales". 
En la segunda parte del informe, titulada "Libertad para vivir sin miseria", el secretario general se ocupa de los temas del desarrollo y la cooperación internacional. Sugiere además que: "Corresponde a cada país en desarrollo la responsabilidad primordial de su propio desarrollo: fortalecer la buena gobernanza, luchar contra la corrupción y adoptar políticas y hacer inversiones que permitan un crecimiento impulsado por el sector privado y aumenten al máximo la disponibilidad de recursos internos para financiar estrategias nacionales de desarrollo".

La doctrina R2P fue asumida por los Jefes de Estado y de Gobierno reunidos en la Cumbre Mundial de las Naciones Unidas, celebrada en Nueva York, en 2005. En efecto, en esta Cumbre Mundial los jefes de Estado aceptaron por unanimidad el concepto de la R2P, de esta forma, se elevó el perfil jurídico de la responsabilidad de proteger cuando todos los Estados Miembros aceptaron oficialmente la responsabilidad de cada Estado de proteger a su población del genocidio, los crímenes de guerra, la depuración étnica y los crímenes de lesa humanidad. La aceptación del principio por consenso en los Párrafos 138, 139 y 140 del Documento Final de la Cumbre convirtió la R2P en una norma obligatoria, según la cual "Cada Estado es responsable de proteger a su población del genocidio, los crímenes de guerra, la depuración étnica y los crímenes de lesa humanidad. Esa responsabilidad conlleva la prevención de dichos crímenes, incluida la incitación a su comisión, mediante la adopción de las medidas apropiadas y necesarias. Aceptamos esa responsabilidad y convenimos en obrar en consecuencia. La comunidad internacional debe, según proceda, alentar y ayudar a los Estados a ejercer esa responsabilidad y ayudar a las Naciones Unidas a establecer una capacidad de alerta temprana."

De acuerdo con esta doctrina, recae sobre el Estado la responsabilidad primordial de proteger a las poblaciones de esos crímenes y que es responsabilidad de la comunidad internacional, actuando a través de las Naciones Unidas, ayudar y alentar al Estado a cumplir con su responsabilidad cuando "es manifiesto que las autoridades nacionales no protegen a sus ciudadanos" de esos crímenes y si fuera necesario la comunidad internacional, a través de las Naciones Unidas, tenía también la "la responsabilidad de utilizar los medios diplomáticos, humanitarios y otros medios pacíficos apropiados, de conformidad con los Capítulos VI y VIII de la Carta", para ayudar a proteger a las poblaciones de esos crímenes. Si esos medios resultan ser inadecuados y si "es evidente que las autoridades nacionales no protegen" a la población, la comunidad internacional debe actuar de manera "oportuna y decisiva" a través del Consejo de Seguridad y de conformidad con el Capítulo VII de la Carta de las Naciones Unidas. En el Documento Final de la Cumbre Mundial se hacía hincapié también en la "necesidad de que la Asamblea General siga examinando la responsabilidad de proteger”.

Este compromiso implicaba que las Naciones Unidas examinaran las formas de proteger a las poblaciones amenazadas y vulnerables mediante el fortalecimiento de la capacidad de la comunidad internacional para detectar y resolver rápidamente los problemas antes de que se agraven. Esas medidas debían incluir esfuerzos diplomáticos para evitar el conflicto; actividades humanitarias para salvar a las poblaciones amenazadas, mejorar sus condiciones de vida y asegurar el respeto de sus derechos, así como otras medidas pacíficas, incluido el fomento de la capacidad de las poblaciones de protegerse a sí mismas o la capacidad de la sociedad para asegurar su protección o hacer declaraciones públicas o intervenciones militares acordadas. Todo ello con el fin de evitar la necesidad de realizar intervenciones militares.

Con posterioridad, el Secretario General realizó en enero de 2009 un informe sobre "Hacer efectiva la R2P"17, el primer (y hasta el momento único) documento exhaustivo de la $\mathrm{ONU}$ en la materia. Este informe urge la operacionalización de la R2P, a través de un "enfoque tripartito", centrando la atención en la alerta temprana y estableciendo recomendaciones sobre los

\footnotetext{
${ }^{17}$ Consultar el Doc. A/63/677.
}

Revista de Direito Brasileira | São Paulo, SP | v. 13 | n. 6 | p. 39 - 60 | jan./abr. 2016 
pasos a seguir. Con el ánimo de aplicar y hacer realidad la doctrina, el Consejo de Seguridad ha ido introduciéndola en sus Resoluciones (la 1674 de 2006, sobre "Protección de Civiles en Conflictos Armados", la 1706 de 2006, sobre la "Crisis en Sudán-Darfur", la 1820 de 2008, sobre "las mujeres, la paz y la seguridad", las 1888 y 1889, de 2009, sobre la misma materia, o la 1894, de 2009, sobre "Protección de Civiles en Conflictos Armados").

\section{LA EXTENSIÓN DE LA R2P AL ÁMBITO DE LA GARANTÍA DE LA SEGURIDAD CLIMÁTICA}

Una vez analizado el concepto de R2P, el siguiente cometido es dilucidar la conveniencia de su aplicación en el ámbito del cambio climático. Ciertamente, la amenaza a la seguridad humana no es suficiente razón por sí misma para justificar la aplicación de la doctrina R2P, como ya se ha analizado, esta se reserva a casos concretos que revisten de especial gravedad. El cometido del análisis, que se realiza a continuación, consiste en determinar cómo las situaciones derivadas del cambio climático justifican la aplicación de la doctrina R2P. Si bien es verdad que el cambio climático y sus efectos no se circunscriben a las situaciones en las que se aplica la doctrina R2P, existen una serie de razones por las cuales hace conveniente su consideración en el ámbito de los desastres climáticos. En primer lugar, el cambio climático puede generar, y de hecho genera, situaciones de especial gravedad y sufrimiento humanitario. En segundo lugar, estas situaciones ponen de manifiesto la incapacidad de los Estados de enfrentarlas individualmente $\mathrm{y}$, por lo tanto, requieren la asistencia de la comunidad internacional para enfrentar la emergencia humanitaria. En tercer lugar, existe la intervención de la comunidad internacional no sólo constituye una necesidad sino también responde a una responsabilidad atribuible a la responsabilidad histórica de los grandes emisores de gases de efecto invernadero, los cuales deben intervenir para asistir a los Estados, cuya población está indefensa, dada la imposibilidad, la incapacidad o la negación de proferir la protección adecuada frente a estos desastres climáticos.

En 1990, un grave terremoto golpeó la provincia de Gilan, en Irán, causando más de 50.000 muertes y destruyendo aldeas enteras ${ }^{18}$, el Gobierno iraní se demoró en solicitar asistencia internacional. De hecho, Irán pidió a la gente que «sobrellevara la prueba con orgullo, paciencia, esfuerzo y solidaridad» ${ }^{19}$. El Gobierno prohibió los vuelos directos de socorro procedentes del exterior y, al principio, exigió que los socorristas se mantuviesen alejados. Pese a que Irán terminó pidiendo asistencia a la comunidad internacional, el retraso provocó la muerte de muchos heridos que hubieran podido ser salvados ${ }^{20}$.

En febrero de 1998, seis días después del terremoto que se cobró 4.500 vidas en Afganistán $^{21}$, había noticias de que las víctimas de Ghanj, la aldea más afectada, no habían recibido ayuda internacional alguna y corrían peligro de muerte por inanición. Aunque la situación se debía en parte al mal tiempo, la asistencia también se vio afectada por la rígida milicia islámica talibán de Afganistán, que controla varios accesos a la región, y por el estricto régimen fronterizo a las órdenes de las tropas rusas en la frontera con Tayikistán ${ }^{22}$.

\footnotetext{
${ }^{18}$ Consultar «When the world shook», The Economist, 30 de junio de 1990, p. 45.

${ }^{19}$ Consultar «The politics of humanitarianism», Time, 9 de julio de 1990, p. 36.

${ }^{20}$ Vid. «Death in the afternoon: Iran's earthquake», The Economist, 8 de marzo de 1997.

${ }^{21}$ Oficina de Coordinación de Asuntos Humanitarios de las Naciones Unidas, «UN, ICRC, seek \$2.5 million for Afghan air drop», Reuters, 12 de febrero de 1998.

${ }^{22}$ Consultar la noticia «Desperate Afghan quake victims await help», Reuters, 10 de febrero de 1998.
} Revista de Direito Brasileira | São Paulo, SP | v. 13 | n. 6 | p. 39 - 60 | jan./abr. 2016 
Otro ejemplo de esta situación fue la producida en Myanmar (la antigua Birmania), en mayo de 2008, cuando el ciclón tropical Nargis azotó el país, barriendo toda la región del delta del Ayeyarwady y la ciudad más poblada del país, Saigón, causando una gran destrucción. Edificios, infraestructuras y comunicaciones resultaron gravemente dañados ${ }^{23}$. Se calcula que el número de afectados llegó a los 2,4 millones de personas, con un número oficial de 77.738 fallecidos y 55.917 desaparecidos, generando una situación de grave emergencia humanitaria ${ }^{24}$. Esta fue sin duda, la mayor catástrofe natural en Asia desde el 'tsunami' de diciembre de 2004.

En ese momento, ante los obstáculos interpuestos por parte del gobierno birmano para recibir ayuda internacional en favor de la población civil, se propuso por primera vez la posibilidad de considerar este rechazo como un crimen contra la humanidad. De este modo, se planteaba invocar la doctrina de la R2P, con la intención de facilitar una respuesta efectiva de la comunidad internacional, que atenuara los efectos y protegiera a las víctimas desatendidas por las autoridades locales.

Situaciones como esta, plantea si la doctrina de la R2P solo puede aplicarse más que para los cuatro casos previstos, es decir, genocidio, crímenes de guerra, limpieza étnica y crímenes contra la humanidad... o bien, si puede extender para otras situaciones, como la acontecida en Afganistán o en Myanmar. Además, si se considera que los episodios más dramáticos ocurridos a raíz del cambio climático ocurrirán con más frecuencia y virulencia azotando a países incapaces de proteger a sus propias poblaciones. Es decir, se podría concebir la aplicación de la doctrina R2P cuando un Estado no quiere o no puede proteger a su población en casos de desastres climáticos? Y, entonces, sería pertinente reconocer la responsabilidad subsidiaria de la comunidad internacional de intervenir para salvaguardar los derechos humanos de esa población?

La cuestión, llegados a este punto, es el análisis de la posibilidad de aplicar en el ámbito ambiental, específicamente, en el caso de los impactos del cambio climático sobre las poblaciones más vulnerables y sobre las cuales el propio Estados se halla incapaz de proporcionar asistencia no parece ni sencilla ni pacífica, por cuanto el concepto mismo de R2P es de por sí controvertido.

El grupo de trabajo sobre cuestiones éticas y humanitarias en el marco de la asistencia humanitaria, instituido en 1994 en virtud del Programa de Asistencia Humanitaria en la Conferencia Mundial sobre Religión y Paz planteó la posibilidad de elaborar un acuerdo internacional. El resultado fueron los criterios Mohonk para la asistencia humanitaria en caso de urgencias complejas ${ }^{25}$. Basándose en estos criterios, el grupo de trabajo instó a los Estados miembros de la ONU a: reconocer el derecho a recibir asistencia humanitaria y la responsabilidad de brindarla, y reconocer y garantizar el derecho de las organizaciones de asistencia humanitaria a tener acceso a las poblaciones en peligro en situaciones complejas de urgencia.

En este sentido, incumbe al propio Estado la responsabilidad principal de proteger a su población: los Estados son directamente responsables del respeto, protección y cumplimiento de los derechos humanos de sus ciudadanos y toda otra persona en su territorio o bajo su

\footnotetext{
${ }^{23}$ Consultar la noticia en El País (Internacional), "El ciclón Nargis deja 10.000 muertos en Myanmar”, 5 mayo 2008. Disponible en línea en: http://internacional.elpais.com/internacional/2008/05/05/actualidad/1209938405_850215.html (recuperado el 4 de abril de 2014).

${ }^{24}$ Consultar el "Ciclón Nargis (Myanmar) Informe sobre la respuesta humanitaria" Mayo 2008-Abril 2009, elaborado por Oxfam: http://www.oxfamintermon.org/sites/default/files/documentos/files/100422_rendicion_myanmar.pdf (Recuperado el 4 de abril 2014).

${ }^{25}$ Consultar a EBERSOLE, J., "The Mohonk criteria for humanitarian assistance", Human Rights Quarterly, ${ }^{\circ} 17$, 1995, p. 192.
}

Revista de Direito Brasileira | São Paulo, SP | v. 13 | n. 6 | p. 39 - 60 | jan./abr. 2016 
jurisdicción, pero cuando la población esté sufriendo graves daños y el Estado no quiera o no pueda atajar o evitar esos sufrimientos, la responsabilidad internacional de proteger tendrá siempre prioridad sobre el principio de no intervención.

El derecho a recibir esta asistencia humanitaria no sólo es coherente con el actual cuerpo normativo internacional en materia de derechos humanos, sino que es necesario para la realización de los derechos humanos fundamentales a la vida, a la alimentación, a la vestimenta y a la vivienda ${ }^{26}$. Estos derechos están claramente estatuidos en el derecho internacional consuetudinario y puede decirse que han alcanzado el grado de jus $\operatorname{cogens}^{27}$. Prestar asistencia y respetar estos derechos en caso de desastre natural es una responsabilidad fundamental del Estado afectado $^{28}$. No obstante, cuando éste no puede proporcionar el socorro y no quiere dar rápidamente permiso para que se envíe asistencia humanitaria desde el exterior, las víctimas tienen derecho a recibir ayuda humanitaria desde el exterior para que se respeten sus derechos fundamentales. Esto, a su vez, supone una obligación correlativa del Estado de permitir el rápido acceso a las víctimas. No se trata sino de hacer cumplir la obligación de cada Estado de garantizar "el respeto universal y la efectividad" 29 del más fundamental de los derechos humanos: el derecho a la vida. Denegar el derecho a recibir asistencia humanitaria del exterior en caso de desastre natural acarrea muchas muertes, tal como ha quedado demostrado en Afganistán, durante los acontecimientos que "conmocionaron la conciencia de la humanidad", puesto que había situaciones contrarias a las "consideraciones de humanidad más elementales" "30.

\section{LA "SOBERANÍA COMO RESPONSABILIDAD” COMO FUNDAMENTO JURÍDICO DE LA R2P}

En su Opinión consultiva sobre el suroeste de África, la Corte Internacional de Justicia indicó lo absurdo que es aplicar mecánicamente normas antiguas sin hacer referencia a los cambios constitutivos fundamentales del sistema jurídico internacional ${ }^{31}$. En este sentido, la

\footnotetext{
${ }^{26}$ En el artículo 4 de la resolución de la Asamblea General sobre el establecimiento de normas internacionales en el ámbito de los derechos humanos se exige que los nuevos derechos humanos que se proponen deben: "Ser congruentes con el conjunto de normas internacionales vigentes en materia de derechos humanos; Tener carácter fundamental y dimanar de la dignidad y el valor inherentes a la persona humana; Ser lo suficientemente precisos para engendrar derechos y obligaciones identificables y observables; Proporcionar, según proceda, un mecanismo de aplicación realista y efectivo que incluya sistemas de presentación de informes; Suscitar amplio apoyo internacional". Vid. Resolución de la Asamblea General de la ONU 41/120, 3 de diciembre de 1986.

${ }^{27}$ Según Shaw, el derecho a la vida puede ser caracterizado como un principio de jus cogens : SHAW, M.N., International Law, Grotius Publications, $3^{a}$ Edición Cambridge, 1991, p. 240. También consultar a AGO, R., «Droit des traités à la lumière de la Convention de Vienne. Introduction», Recueil des Cours, 1971, núm. 3, p. 324.

${ }^{28}$ Decenio Internacional para la Reducción de los Desastres Naturales, Resolución de la Asamblea General de la ONU 49/22, 13 de diciembre de 1994, Preámbulo; Fortalecimiento de la capacidad del sistema de las Naciones Unidas para responder en situaciones de desastres naturales y de otra índole, Resolución de la Asamblea General de la ONU 36/225, 17 de diciembre de 1981, Principio 2; Asistencia humanitaria a las víctimas de desastres naturales y situaciones de emergencia similares, Resolución de la Asamblea General 43/131, 8 de diciembre de 1988, Principio 2; Asistencia humanitaria a las víctimas de desastres naturales y situaciones de emergencia similares, Resolución de la Asamblea General de la ONU 45/100, 14 de diciembre de 1990, Principio 2; Beigbeder, Y., The role and status of international humanitarian volunteers and organizations: The right and duty to humanitarian assistance, Martinus Nijhoff Publishers, Londres, 1991, p. 9.

${ }^{29}$ Art. 55 de la Carta de las Naciones Unidas.

${ }^{30}$ Corfu Channel (UK v. Albania), ICJ Rep. 1949, p. 22.

${ }^{31}$ South-West Africa — Voting procedure (Advisory Opinion), ICJ Rep., 1955, p. 77, M. MCDOUGAL, H. LASSWELL \& J. MILLER, The Interpretation of agreements and World Public Order, Yale University Press, New Haven, 1967, capítulo 4.
}

Revista de Direito Brasileira | São Paulo, SP | v. 13 | n. 6 | p. 39 - 60 | jan./abr. 2016 
superación de viejos anacronismos exige la actualización de las normas como la de la soberanía del Estado, deben ser interpretadas nuevamente a la luz de este cambio constitutivo.

La posibilidad de aplicar la doctrina R2P a las situaciones de catástrofes climáticas parte de la idea tradicional de soberanía, pero entendida como responsabilidad. La "soberanía como responsabilidad" constituye, por una parte, el centro neurálgico de la responsabilidad de proteger a la propia población víctima de los desastres climáticos y, por otra, la responsabilidad de los Estados industrializados de proteger a la población de los no industrializados, por la emisión presente e histórica de gases de efecto invernadero generadores de los cambios climáticos.

La soberanía como R2P exigiría que los Estados concedan a terceros Estados el derecho a tener acceso a sus territorios caso de desastre natural. La protección de la población civil en caso de desastre climático corresponde, en primer lugar, al propio Estado. Cuando las víctimas de un Estado no reciban la asistencia humanitaria necesaria para sobrevivir y preservar la dignidad en situación de desastre climático, el Estado receptor deberá permitir que presten la ayuda organizaciones habilitadas.

Es evidente, que la creación de un derecho de este tipo afecta a la soberanía nacional de un Estado. No obstante, hay que buscar un término medio entre la urgente necesidad de prestar ayuda a las víctimas y la soberanía del Estado. Esta cuestión es reconocida en los Criterios de Mohonk, donde se indica que: "los principios de no intervención y soberanía no debieran emplearse para obstaculizar la asistencia humanitaria. El objetivo de la asistencia humanitaria es salvar vidas y no cuestionar al Estado en cuyo territorio ha de distribuirse la ayuda"32. Esto se debe, en primer lugar, a que la asistencia humanitaria puede ser considerada como "un esfuerzo internacional para aliviar el sufrimiento de los hombres"33. Al respecto, la Corte Internacional de Justicia en el caso de las Actividades militares y paramilitares en Nicaragua y contra Nicaragua define la asistencia humanitaria en términos de una de las principales organizaciones de socorro neutrales no gubernamentales, a saber, la Cruz Roja: "Para que la «asistencia humanitaria» no sea condenada como una injerencia (...) no solamente hay que limitarla al propósito refrendado por la experiencia de la Cruz Roja, es decir, "evitar y paliar los sufrimientos de las víctima s»y «proteger la vida y la salud, y asegurar el respeto del ser humano", sino que, además y sobre todo, debe brindarse a todas las personas que la necesiten, sin discriminación alguna"34. En este sentido, si se restringe la obligación de permitir el acceso a solamente a las organizaciones de socorro no gubernamentales y neutrales, se puede evitar que surjan sentimientos nacionalistas y que la intervención en favor de las víctimas sea considerada como injerencia de otro Estado ${ }^{35}$.

La Resolución 46/182 de la Asamblea General, el 19 de diciembre del año 1991. Con principios rectores como: "1. La asistencia Humanitaria reviste importancia fundamental para las víctimas de desastres naturales y otras emergencias. 2. La asistencia humanitaria deberá proporcionarse de conformidad con los principios de humanidad, neutralidad e imparcialidad. 3. Deberán respetarse plenamente lasoberanía, la integridad territorial y la unidad nacional de los Estados, de conformidad con la Carta de las Naciones Unidas. En este contexto la asistencia humanitaria deberá proporcionarse con el consentimiento del país afectado y, en principio, sobre la base de una petición del país afectado."

\footnotetext{
${ }^{32}$ J. EBERSOLE, op. cit., p. 198.

${ }^{33}$ MACALISTER-SMITH, P., International humanitarian assistance, Martinus Nijhoff Publishers, Boston, 1985 , p. 72.

${ }^{34}$ Ibid., p. 125.

${ }^{35}$ Una organización habilitada a tales efectos sería una organización no gubernamental no alineada ni relacionada con un Gobierno; con probada experiencia en la efectiva provisión de asistencia humanitaria, y registrada en la Oficina de Coordinación de Asuntos Humanitarios de las Naciones Unidas como organización de socorro humanitario en situaciones de desastre.
}

Revista de Direito Brasileira | São Paulo, SP | v. 13 | n. 6 | p. 39 - 60 | jan./abr. 2016 
En su $5^{\circ}$ período de sesiones (2007), la Comisión de Derecho Internacional de las Naciones Unidas decidió incluir el tema "Protección de las personas en casos de desastre" en su programa de trabajo y nombró Relator Especial al Sr. Eduardo Valencia Ospina. En su 61 ${ }^{\circ}$ período de sesiones, en 2009, la Comisión examinó el segundo informe del Relator Especial (A/CN.4/615 y Corr.1), en el que se analizaban el alcance del tema ratione materiae, ratione personae y ratione temporis y cuestiones relacionadas con la definición de "desastre" a efectos de ese tema y se abordaba el estudio del deber fundamental de cooperar ${ }^{36}$.En su $63^{\circ}$ período de sesiones (2011), la Comisión aprobó provisionalmente los proyectos de artículo 6 a 9 en la 3102a sesión, celebrada el 11 de julio de 2011. La Comisión tuvo ante sí el cuarto informe del Relator Especial (A/CN.4/643 y Corr.1), que contenía, entre otras cosas, un examen de la responsabilidad del Estado afectado de buscar asistencia cuando su capacidad nacional de respuesta se vea superada, del deber del Estado afectado de no denegar arbitrariamente su consentimiento para la asistencia externa, y el derecho de la comunidad internacional a ofrecer asistencia ${ }^{37}$.

En este sentido, en el "Texto de los proyectos de artículo sobre la protección de las personas en casos de desastre" aprobados hasta el momento por la Comisión ${ }^{38}$, son relevantes los artículos de 9 a 11 relativos al "Papel del Estado afectado". El artículo 9 se refiere a que el Estado afectado, en virtud de su soberanía, tendrá el deber de asegurar la protección de las personas y la prestación de socorro y asistencia en casos de desastre en su territorio. Asimismo, corresponde al Estado afectado el papel principal en la dirección, el control, la coordinación y la supervisión de dicho socorro y asistencia. Y el artículo 10 se refiere al deber del Estado afectado de buscar asistencia de terceros Estados, las Naciones Unidas,otras organizaciones intergubernamentales competentes y organizaciones nogubernamentales pertinentes cuando el desastre supere su capacidad nacional de respuesta. La prestación de esta asistencia, de acuerdo con el artículo 11, requerirá el consentimiento del Estado afectado, que en todo caso no se denegará arbitrariamente ${ }^{39}$.

Finalmente, es recurrente mencionar la Resolución de la Asamblea General, A/RES/68/168, de 18 de Diciembre de 2013, relativa a "La globalización y sus consecuencias para el pleno disfrute de todos los derechos humanos", relevante en este caso, ya que si bien la globalización puede afectar a los derechos humanos porque repercute, entre otras cosas, en la función del Estado, la promoción y protección de todos los derechos humanos es ante todo responsabilidad del Estado ${ }^{40}$.

Respecto de la responsabilidad,que incumbe a los Estados de proteger a la población afectada por un desastre climático, por la emisión presente e histórica de gases de efecto invernadero generadores de los cambios climáticos, existe también una laguna jurídica que

\footnotetext{
${ }^{36} \mathrm{El}$ informe contenía además propuestas para los proyectos de artículo 1 (Alcance), 2 (Definición de desastre) y 3 (Deber de cooperar).

${ }^{37}$ En el informe se hacían propuestas para los otros tres proyectos de artículo siguientes: proyectos de artículo 10 (Deber del Estado afectado de buscar asistencia), 11 (Obligación del Estado afectado de no denegar arbitrariamente su consentimiento) y 12 (Derecho a ofrecer asistencia). La Comisión aprobó provisionalmente los proyectos de artículo 10 y 11 en la $3116^{\text {a }}$ sesión, celebrada el 2 de agosto de 2011, si bien no pudo concluir el examen del proyecto de artículo 12 por falta de tiempo.

${ }^{38}$ Para los comentarios a los proyectos de artículo 1 a 5, véase Documentos Oficiales de la Asamblea General, sexagésimo quinto período de sesiones (A/65/10), párr. 331. Para los comentarios a los proyectos de artículo 6 a 11 , véase Documentos Oficiales de la Asamblea General, sexagésimo sexto período de sesiones (A/66/10), párr. 289.

${ }^{39}$ Vid. Report of the International Law Commission Sixty-fourth session (7 May-1 June and 2 July-3 August 2012) General Assembly Official Records Sixty-seventh session Supplement No. 10 (A/67/10), pp. 47-81. Disponible en línea en: http://legal.un.org/ilc/reports/2012/All_languages/A_67_10_E.pdf (recuperado el 5 de abril de 2014).

${ }^{40}$ Consultar el texto de la Resolución en línea en: http://www.un.org/en/ga/search/view_doc.asp?symbol=A/68/PV.70\&Lang=S (recuperado el 5 de abril de 2014).
}

Revista de Direito Brasileira | São Paulo, SP | v. 13 | n. 6 | p. 39 - 60 | jan./abr. 2016 
explicite el vínculo de obligatoriedad en la prestación de esta asistencia. No obstante, desde el ámbito del Derecho ambiental existen una serie de preceptos normativos, que consuetudinariamente, se han asentado para comprometer y responsabilizar a los Estados, que llevan a cabo actividades nocivas para el medio ambiente y que generan emergencias humanitarias, a que asuman sus responsabilidades sobre la base de la doctrina R2P, es decir, asumir la responsabilidad en la prevención, reacción y recuperación de las poblaciones de otros Estados víctimas de las alteraciones climáticas.

Respecto a la responsabilidad de prevenir se sustenta en relación con el deber de protección del medio ambiente, el principio de cooperación y el principio de prevención. Todos estos principios resultan convenientemente aplicables para fundamentar la exigencia de protección de los Estados en caso de desastres climáticos, porque todos y cada uno de estos principios se dirigen a la protección del medio ambiente frente a los posibles daños ambientales. Así, el deber de proteger el medio ambiente consiste en la obligación general de los Estados de proteger el medio ambiente ${ }^{41}$. Si bien este principio tiene un carácter general y es aplicable a todos los sectores del medio ambiente, no ha sido mencionado a menudo en los textos positivos ${ }^{42}$. Tan sólo el artículo 30 de la Carta de Derechos y Deberes Económicos de los Estados establece, expresamente, el diferente trato que deben recibir los Estados en relación con su responsabilidad en la protección del medio ambiente. En concreto establece que "La protección, la preservación y la mejora del medio ambiente para las generaciones presentes y futuras es responsabilidad de todos los Estados. Las políticas ambientales de todos los Estados deben procurar la mejora y no afectar de modo adverso al desarrollo presente y futuro de los países en vías de desarrollo (...)”. El artículo 25 aun pone más énfasis en la necesidad de que todos los Estados deben prestar especial atención a las necesidades particulares y a los problemas de los Estados menos desarrollados, a los Estados en transición y a aquellos pequeños Estados insulares en vías de desarrollo $^{43}$. También, la Carta Mundial de la Naturaleza, adoptada y, solemnemente, proclamada por la Asamblea General de las Naciones Unidas, en su Resolución 37/7, de 28 de octubre de $1982^{44}$ establece que la actividad humana, por sus actos o las consecuencias de éstos, dispone de los medios para transformar la naturaleza y agotar sus recursos y, por ello, debe reconocer la urgencia que requiere el mantenimiento del equilibrio, la calidad de la naturaleza y la conservación de los recursos naturales.

El principio de cooperación se refiere al deber general de los Estados de proteger el medio ambiente se vincula directamente con el principio de cooperación. Este deber se incluye en el Principio 24 de la Declaración de Estocolmo cuando establece que "Todos los países, grandes o pequeños, deben ocuparse con espíritu de cooperación y en pie de igualdad de las cuestiones internacionales relativas a la protección y mejoramiento del medio"45. El principio de

\footnotetext{
${ }^{41} \mathrm{Al}$ respecto, KISS entiende que “... el primero de los principios que se desprenden es el deber de todos los Estados de proteger y preservar el medio ambiente, no solamente en sus relaciones con otros Estados, sino también en los espacios sometidos a sus competencias así como en aquellos que no están sometidos a ninguna competencia territorial". Vid.KISS, A., "Droit international de l'environnement", 146 Jurisclasseur de droit international, 1994, p. 11.

42 No obstante, este principio ha sido proclamado con claridad en el artículo 192 del Convenio de las Naciones Unidas sobre Derecho del Mar de 1982, cuando establece que "todos los Estados tienen el deber de proteger y preservar medio ambiente marino".

${ }^{43}$ AGNU Res 3281 (XXIX) (12 Dec. 1974).

${ }^{44} \mathrm{~A} / \mathrm{RES} / 37 / 7$. Disponible en línea en: http://www.un.org/es/comun/docs/?symbol=A/RES/37/7\&Lang=S (recuperado el 30 de abril 2014).

${ }^{45}$ La misma exigencia figura en UNGA Res 3129 (XXVIII) (13 Dec. 1973); en los principios del PNUMA de 1978 sobre la cooperación ambiental relativa a los recursos naturales compartidos entre dos o más Estados (UNEP GC Dec 6/14), en el Preámbulo de la Carta Mundial de la Naturaleza de 1982 y en el principio 21 de la misma (UN Doc A/RES/37/7, 28 Oct. 1982).
}

Revista de Direito Brasileira | São Paulo, SP | v. 13 | n. 6 | p. 39 - 60 | jan./abr. 2016 
cooperación desde esta perspectiva permite afirmar el deber de intercambiar información relevante para la protección del medio ambiente y el de desarrollar actividades de promoción de la investigación científica y tecnológica, procurar asistencia técnica y financiera a los países en desarrollo, establecer programas de vigilancia, evaluación ambiental, etc. Otra manifestación del principio de cooperación es el deber de los Estados de notificar prontamente y prestar asistencia a otros Estados en situaciones de emergencia que pueden producir consecuencias ambientales dañosas. Por ejemplo, se puede citar los Convenios adoptados, bajo los auspicios del OEIA, tras el accidente de Chernóbil, el 26 de abril de 1986, sobre la pronta notificación de accidentes nucleares y sobre la asistencia en caso de accidente nuclear o emergencia radiológica, ambos adoptados el 15 de agosto de 1986. También, el Principio 18 de la Declaración de Río ha afirmado a este respecto que "Los Estados deberán notificar inmediatamente a otros Estados de los desastres naturales u otras situaciones de emergencia que puedan producir efectos nocivos súbitos en el medio ambiente de esos Estados. La Comunidad internacional deberá hacer todo lo posible para ayudar a los Estados que resulten afectados".

El principio de prevención consiste en, por una parte, la obligación de evitar el daño ambiental in genere y, por otra, en no permitir que el territorio de los Estados sea utilizado de manera que cause un perjuicio a otros Estados ${ }^{46}$. La fundamentación de este principio radica en la idea de la diligencia debida ${ }^{47}$, del uso equitativo de los recursos y, en definitiva, en la buena $\mathrm{fe}^{48}$. Esta obligación de no permitir que el territorio de los Estados sea utilizado de manera que cause un perjuicio a otros Estados fue establecida, por primera vez, por la jurisprudencia internacional en los asuntos del Estrecho de $\operatorname{Corfú}^{49}$ y, en el ámbito ambiental, de la Fundición de Trail ${ }^{50}$, constituyendo los antecedentes clásicos en esta materia. También en los asuntos del Gut Dam Claims $^{51}$, sobre la legalidad de la amenaza o el uso de las armas nucleares ${ }^{52}$ y Gabcíkovo-

\footnotetext{
${ }^{46}$ El principio de prevención se puso de relieve en el laudo relativo a la Fundación de Trail y fue reiterado no sólo en el Principio 21 de la Declaración de Estocolmo (UN Doc A/CONF.48/14/Rev.1) y en el Principio 2 de la Declaración de Río (UN Doc A/CONF.151/26/Rev.1/Vol.I), sino también en la UNGA Res 2995 (XXVII) (15 Dec. 1972), relativa a la cooperación en el campo del medio ambiente. Este principio también se recoge en el Principio 3 del Proyecto de Principios de conducta en el campo del medio ambiente para orientar a los Estados en la conservación y la explotación armoniosa de los recursos naturales compartidos por dos o más Estados. Vid.UNEP GC Dec 6/14 (19 May 1978) (UN Doc A/33/25).

${ }^{47}$ La obligación de observar la diligencia debida constituye la norma básica de la protección del medio ambiente contra los daños, como puede deducirse de varias convenciones internacionales, así como de las resoluciones e informes de conferencias y organizaciones internacionales. Véase, por ejemplo, el art. 2 del Convenio de Viena para la protección de la capa de ozono de 1987. Respecto a resoluciones e informes de conferencias y organizaciones internacionales véase, por ejemplo, el Principio 21 de la Carta Mundial de la Naturaleza (UNGA Res 37/7).

${ }^{48}$ Según el Comentario al texto del Proyecto de artículos sobre prevención del daño transfronterizo resultante de actividades peligrosas, cit. supra, "El principio de buena fe es parte integrante de toda obligación de consulta y negociación. (...) Las partes evidentemente intentarán primero seleccionar aquellas medidas que puedan evitar el riesgo de causar daños transfronterizos sensibles o, si esto no es posible, que minimicen el riesgo de causarlos".

${ }^{49}$ En este caso, la CIJ afirmó que “... ciertos principios generales bien reconocidos (establecen) la obligación de todo estado de no permitir la utilización de su territorio para la realización de actos contrarios a los derechos de otros Estados". Vid. CIJ, Recueil 1949, p. 22.

${ }^{50}$ El Tribunal de arbitraje del caso de la Fundición de Trail afirmó que, en particular, “... debe exigirse a la Fundición de Trail que se abstenga de causar daño alguno con sus humos en el Estado de Washington". También entendió que "Según los principios del Derecho internacional (...), ningún Estado tiene derecho a usar o permitir que se use su territorio de modo que se causen daños (...) en el territorio de otro o a la propiedad de las personas que allí se encuentran, cuando se trata de un supuesto de consecuencias graves y el daño quede establecido por medio de una prueba clara y convincente". Vid. Trail Smelter Arbitration Case (USA/Canadá), Award of March 11, 1941. RIAA, vol. III, pp. 1965 y ss., especialmente pp. 1974-1980.

${ }^{51}$ Vid. Gut Dam Case (Canadá/Estados Unidos), Decisiones de 15 de enero de 1968, de 12 de febrero de 1968 y de 27 de septiembre de 1968. Lake Ontario Claims Tribunal, ILM, vol. 8 (1969), pp. 118-143.
}

Revista de Direito Brasileira | São Paulo, SP | v. 13 | n. 6 | p. 39 - 60 | jan./abr. 2016 
Nagymaros ${ }^{53}$. La Declaración de Estocolmo de 1972, recoge en su Principio 21 esta obligación de prevención al igual que el Principio 2 de la Declaración de Río $1992^{54}$.La Corte Internacional de Justicia confirmó posteriormente a través de la Opinión consultiva de 1996 sobre la Legalidad de la amenaza o uso de armas nucleares que: "La existencia de una obligación general de los Estados de asegurar que las actividades llevadas a cabo en su jurisdicción o bajo su control respeten el medio ambiente de otros Estados o de otras áreas situadas más allá del control nacional constituye parte del corpus del Derecho internacional del medio ambiente" ${ }^{\text {.55 }}$. Este mismo dictum fue reiterado en el Asunto Gabčíkovo-Nagymaros, de 25 de septiembre de 1997 , en el que se establece que "La Corte no pierde de vista, en el ámbito de protección ambiental, que la vigilancia y la prevención se imponen en razón de su carácter, en ocasiones, irreversible, de los daños causados al medio ambiente y de los límites inherentes al mecanismo propio de reparación de este tipo de daños..."

Además, en esta vertiente preventiva de la R2P, es necesario mencionar el principio de precaución, incluido en el Principio 15 de la Declaración, que implica la obligación de los Estados de adoptar medidas eficaces para impedir la degradación del medio ambiente, cuando exista peligro de daño grave o irreversible, a pesar de la ausencia de certeza científica absoluta de pueda o no originarse ese daño. En definitiva, no se debe posponer una medida por el simple hecho de que no se disponga de una información científica completa. Al respecto, es importante tener en cuenta la relación entre la capacidad científica, que poseen sobre todo todos los Estados más desarrollados, y la protección ambiental, que interesa por igual a todos los países, que se

\footnotetext{
${ }^{52}$ En su dictamen consultivo de 8 de julio de 1996, el Tribunal Internacional de Justicia afirmó que “...la existencia de una obligación general a cargo de los Estados de asegurarse de que las actividades que se llevan a cabo bajo su jurisdicción y control respeten el medio ambiente de otros Estados o de zonas no sometidas a control nacional forma ya parte del corpus del Derecho internacional del medio ambiente”. Vid. CIJ Recueil, 1996, pp. 241-2, párrafo 29.

${ }^{53}$ En la Sentencia del Tribunal Internacional de Justicia de 25 de septiembre de 1997, el TIJ cita el principio para poner de manifiesto “... la gran significación que tiene, según su opinión, la protección del medio ambiente no sólo para los Estados sino también para toda la Humanidad”. Vid. Sentencia de la Corte Internacional de Justicia Gabcíkovo-Nagymaros, C.I.J, Recueil, 1997, párrafo 53. A pesar que estas decisiones constituyan un obiter dicta, con estas decisiones, para el TIJ resulta indiscutible que, en 1996-1997, los Principios 21 de la Declaración de Estocolmo y 2 de la Declaración de Río forman parte del Derecho internacional general.

${ }^{54}$ En concreto dispone que "De conformidad con la Carta de Naciones Unidas y los principios del derecho internacional, los Estados tienen el derecho soberano de aprovechar sus propios recursos según sus propias políticas ambientales y de desarrollo y la responsabilidad de velar porque las actividades realizadas dentro de su jurisdicción o bajo su control no causen daños al medio ambiente de otros Estados o de zonas que estén fuera de los límites de la jurisdicción nacional". En el mismo sentido, la Parte V de la Convención sobre el Derecho del Mar de 1982, los arts. 20 y ss. de la Convención sobre el derecho de los usos de los cursos de agua para fines distintos de la navegación, de Nueva York, de 21 de mayo de 1997 y, en el marco del Derecho europeo, la Convención sobre protección y utilización de los cursos de agua transfronterizos y de los lagos internacionales, adoptado en Helsinki, el 17 de marzo de 1992. También se reitera en el Principio 3 del Proyecto de Principios sobre la conducta en el ámbito del medio ambiente que deben observar los Estados en la conservación y la utilización armoniosa de los recursos naturales compartidos por dos o más Estados, hecho en Nairobi, el 19 de mayo de 1978 UNGA Res 3129 (XXVIII). También la Asociación de Derecho Internacional (ILA) en su Declaración de Seúl de 1986 reitera esta obligación de los Estados. Vid. "Declaration on the Progressive development of Principles of Public International Law relating to a New International Economic Order", en ILA, The Report of the Sixty-Second Conference, Seúl, 1986, § 5. Esta norma también se encuentra en el artículo 30 de la Carta de Derechos y Deberes Económicos de los Estados, de 1974 (UNGA Res 3281 (XXIX)), así como en la Acta Final de Helsinki (Conferencia sobre la Seguridad y Cooperación en Europa (CSCE-OSCE), Acta Final, de 1 de agosto de 1975, en 14 ILM 1292, de 1975).

${ }^{55}$ Vid. Legality of the Threat or Use of Nuclear Weapons, I.C.J. Reports 1996, pp. 241-242, párrafo 29.

${ }^{56}$ Cit. supra. Párrafo 53 de la Sentencia. On this issue, see A. Boyle. 'The Gabčíkovo-Nagymaros Case: New Law in Old Bottles' ibid13;P. Sands. 'International Courts and the Application of the Concept of "Sustainable Developement"' (1999) 3 Max-Planck Yearbook of United Nations Law 389;S. Stec and G. Eckstein. 'Of Solemn Oaths and Obligations: Environmental Impact of the ICJ's Decision in the Case Concerning the GabčíkovoNagymaros Project' (1997) 8 Ybk Intl Envtl L 41.
}

Revista de Direito Brasileira | São Paulo, SP | v. 13 | n. 6 | p. 39 - 60 | jan./abr. 2016 
traduce en un diferente grado de obligatoriedad por parte de quién tiene una capacidad científica más avanzada en la adopción de medidas o no en la protección del medio ambiente y, por tanto, responsabilidad en la evitación del daño.

Estos principios, aplicados al presente análisis, implican que los Estados industrializados, principales emisores de gases invernadero deben asistir a los Estados no emisores de gases de efecto invernadero en la prevención de los posibles impactos o consecuencias más allá de su territorio.

En el caso de las responsabilidades de reacción y reparación, la obligatoriedad asistencial de los grandes emisores de gases de efecto invernadero se sustenta, precisamente, por la vulneración misma de su responsabilidad de prevenir el daño ambiental. En este caso, la atribución de la responsabilidad por las emisiones históricas de gases de efecto invernadero y la obligatoriedad de respuesta frente a una catástrofe climática se sustenta básicamente en el principio de las responsabilidades comunes, pero diferenciadas y en el principio de quien contamina, paga mencionados por la delegación de Brasil en su propuesta presentada durante las negociaciones del Protocolo de Kioto, en mayo 1997, en base a la cual debían establecerse diferentes niveles de emisión en relación al impacto producido en la elevación de la temperatura como consecuencia de sus emisiones históricas ${ }^{57}$.

Elprincipio de responsabilidades comunes pero diferenciadas, contenido en el Principio 7 de la Declaración de Río de 1992, reconoce que "Los Estados deberán cooperar, con espíritu de solidaridad mundial para conservar, proteger y restablecer la salud y la integridad del ecosistema de la Tierra. En vista de que han contribuido en distinta medida a la degradación del medio ambiente mundial, los Estados tienen responsabilidades comunes pero diferenciadas. Los países desarrollados reconocen la responsabilidad que les cabe en la búsqueda internacional del desarrollo sostenible, en vista de las presiones que sus sociedades ejercen en el medio ambiente mundial y de las tecnologías y los recursos financieros de que disponen". El principio reconoce las diferencias históricas en la contribución de los Estados desarrollados y en vías de desarrollo a los problemas ambientales globales y diferencias en su respectiva capacidad económica y técnica para hacer frente a dichos problemas ${ }^{58}$.

La carga desigual de los efectos del cambio climático se refleja en el artículo 3 de la Convención Marco sobre Cambio Climático. En él se establece que las Partes deberían proteger el sistema climático "sobre la base de la equidad y de conformidad con sus responsabilidades comunes pero diferenciadas y sus respectivas capacidades", que los países desarrollados "deberían tomar la iniciativa en lo que respecta a combatir el cambio climático y sus efectos adversos" y que deberían tenerse plenamente en cuenta las necesidades de los países en desarrollo, especialmente aquellos "que son particularmente vulnerables a los efecto adversos del cambio climático" y "que tendrían que soportar una carga anormal o desproporcionada en virtud de la Convención".

La carga desigual se traduce en responsabilidades diferenciadas y en la necesidad de asumir compromisos mucho más exigentes en proporción a la mayor contribución a la alteración

\footnotetext{
${ }^{57}$ Consultar "Implementation of the Berlin Mandate. Additional proposals from Parties". Addendum. Note by the secretariat. Proposed elements of a Protocol to the United Nations Framework Convention on Climate Change, presented by Brazil in response to the Berlin Mandate. FCCC/AGBM/1997/MISC.1/Add.3.

${ }^{58}$ En el ámbito del cambio climático se reconoce, en particular, que la naturaleza mundial del cambio climático requiere la cooperación más amplia posible de todos los países y su participación en una respuesta internacional efectiva y apropiada, de conformidad con sus responsabilidades comunes, aunque diferenciadas, sus capacidades respectivas y sus condiciones sociales y económicas. Vid. Resolución sobre la Protección del clima mundial para las generaciones presentes y futuras, UN-Res. A/Res/57/257, de 27 de febrero de 2003.
}

Revista de Direito Brasileira | São Paulo, SP | v. 13 | n. 6 | p. 39 - 60 | jan./abr. 2016 
del sistema climático. La voluntad de hacer eficaz esta responsabilidad conlleva la aplicación de otro principio, el de quien contamina paga. Según este principio, el agente contaminador, en este caso los Estados emisores de gases de efecto invernadero debe cargar con los costos de la contaminación, teniendo debidamente en cuenta el interés público y sin distorsionar el comercio ni las inversiones internacionales.Este principio constituye un axioma muy importante para la obligación de reparación en la R2P, a través de la asignación de responsabilidades y el reconocimiento de compensaciones, especialmente, a través de la asistencia a las emergencias humanitarias producidas por las alteraciones climáticas.

El complemento a este principio es el Principio 13 de la Declaración de Río, por la que los Estados deberán elaborar los instrumentos jurídicos nacionales e internacionales relativos a la responsabilidad y la indemnización respecto de las víctimas de la contaminación y otros daños ambientales.

Estos principios son axiomas, que a modo de un soft law informan la elaboración de políticas, guían el comportamiento de los Estados en sus relaciones internas e internacionales y refuerzan las normas internas e internacionales, siendo su efectividad un tanto variable y su naturaleza jurídica ambigua.

\section{REFLEXIONES FINALES: DE LA INTERVENCIÓN HUMANITARIA A LA R2P}

El aumento de la frecuencia e intensidad de los desastres naturales relacionados con la alteración del sistema climático, junto con la posibilidad creciente de que algunos Estados o bien no están en condiciones de prestar ayuda a las víctimas de desastres naturales o bien no han querido aceptar con prontitud la asistencia humanitaria procedente del extranjero, plantea el reconocimiento de extender la obligación de la R2P, propia de las emergencias humanitarias. Ante esta posibilidad, sería exigible en primer lugar como deber del propio Estado a proteger a su población frente a las calamidades climáticas y, subsidiariamente, ante la incapacidad de cumplir con este deber, la obligación del resto de la comunidad internacional, pero muy especialmente de aquéllos Estados responsables de la generación del cambio climático por su contribución al aumento del nivel de emisiones mundiales de los gases de efecto invernadero responsables del cambio de sistema climático. El reconocimiento de estas responsabilidades tiene como finalidad el garantizar que toda persona tenga derecho a solicitar y recibir de las organizaciones gubernamentales o de las organizaciones habilitadas la ayuda humanitaria que necesite para sobrevivir y mantener la dignidad en una situación de desastre natural generado por el cambio climático. Ahora bien, en situaciones de desastres o catástrofes generadas por el cambio climático, la obligación de prestar asistencia por parte del resto de Estados debe someterse a una seria de precisiones, considerando si esta intervención debe ser subsidiaria y si deben intervenir todo el resto de Estados. Después de haber considerado la diferente contribución de los Estados industrializados en la alteración del clima y las implicaciones sobre los Estados menos desarrollados, sería justo esperar un mayor nivel de compromiso y responsabilidad en la prevención, reacción y recuperación de los Estados vulnerables al impacto climático, si tener que dicha responsabilidad sea subsidiaria, en todo caso debería ser inmediata o simultanea a la responsabilidad asistencial del Estado afectado o potencialmente afectado.

La extensión de la R2P a las situaciones de emergencia humanitaria o de riesgo que se produzcan por la amenaza de las consecuencias del cambio climático exige un planteamiento más amplio del concepto de seguridad humana, para considerar el cambio climático como uno de los grandes desafíos a los que se enfrenta la sociedad internacional y al que deberá destinar la mayor 
parte de las capacidades, recursos y esfuerzos para prevenir los riesgos y reparar los eventuales daños que se produzcan.

Además, con el fin de lograr el respeto del derecho a recibir ayuda humanitaria, debe trascender a cuestiones políticas de intervencionismo estatal. Las organizaciones neutrales no gubernamentales necesitan poder tener acceso a los países donde el respectivo Gobierno no puede o no quiere proporcionar socorro. Es esencial contar con una disposición en la que se establezca el derecho de acceso, porque los desastres naturales tienen lugar cada vez más a menudo en países en desarrollo, que no cuentan con los recursos económicos necesarios para brindar una asistencia que garantice la supervivencia de sus ciudadanos. Limitar este derecho de acceso solo a las organizaciones neutrales no gubernamentales permite sortear las usuales objeciones basadas en la soberanía de los Estados. Una vez que los Estados acepten que su soberanía no se ve necesariamente amenazada, cabe esperar que la presión ejercida por la comunidad internacional y las organizaciones no gubernamentales los incite en un futuro, esperemos que próximo, a ser partes en un convenio sobre asistencia humanitaria en casos de desastres naturales.

\section{REFERENCIAS BIBLIOGRÁFICAS}

ANNAN, K., Informe del Milenio Naciones Unidas. New York, 2000.

AÑAÑOS MEZA, C., "La "responsabilidad de proteger" en Naciones Unidas y la doctrina de la "responsabilidad de proteger", Anuario Mexicano de Derecho internacional,

BALLBÉ MALLOL, M., Seguridad Integral. Un nuevo concepto. Madrid: Instituto Superior de Estudios de Seguridad, 2003.

BERMEJO GARCÍA, R., LÓPEZ-JACOISTE DÍAZ, E., "De la intervención por causas humanitarias a la responsabilidad de proteger. Fundamentos, similitudes y diferencias", INSTITUTO ESPAÑOL DE ESTUDIOS ESTRATÉGICOS, La respuesta del derecho internacional a los problemas actuales de la seguridad global, Ministerio de Defensa, Cuadernos de Estrategia, n. 160, enero 2013.

EVANS, G., "La responsabilidad de proteger", Revista de la OTAN, invierno de 2002.

GARCÍA PÉREZ, R., "La `responsabilidad de proteger': un nuevo papel para Naciones Unidas en la gestión de la seguridad internacional", 11 Revista Electrónica de Estudios Internacionales, 2006.

HARDCASTLE, R. J., CHUA, A. T. L, "Asistencia humanitaria: hacia el derecho de tener acceso a las víctimas de desastres naturales”, Revista Internacional de la Cruz Roja, 1998.

HELLY, D., A., "The EU and the R2P: Towards Pragmatic International Subsidiarity?",Internationale Politik und Gesellschaft, 1/2009.

HILPOLD, P., "The Duty to Protect and the Reform of the UN A New Step in the Development of International Law?", 10 Max Planck Yearbook of United Nations Law, 2006. 
KALDOR, M., Las nuevas guerras. Violencia organizada en la era global, Barcelona, Tusquets Editores, 2001.

LÓPEZ-JACOISTE DÍAZ, E., "La responsabilidad de proteger: reflexiones sobre su fundamento y articulación", Anuario Español de Derecho Internacional, vol. XXII, 2005.

MOLIER, G., "Humanitarian Intervention and the Responsibility to Protect After 9/11", Netherlands International Law Review, vol. LIII, 2006.

MOONEY, E., “Los Principios Rectores y la responsabilidad de proteger”, Revista Migraciones Forzadas, N. especial (dic. 2008). ISSN 1460-9819.

MURITHI, T., “The African Union's transition from non-intervention to non-indifference: an ad hoc approach to the Responsibility to Protect?" International Politics and Society, núm. 1, 2009.

NEWMAN, E., "Humanitarian Intervention, Legality and Legitimacy", The International Journal of Human Rights, 6, 2002.

ÖZDEN, M., ASTRUC, M., "Responsabilidad de proteger: ¿progreso o retroceso del Derecho Internacional Público?”, Cuaderno crítico, núm 12, CETIM, diciembre 2013.

REVILLA MONTOYA, P., "Hacia la responsabilidad para proteger. Bases jurídicas para una respuesta colectiva ante crisis humanitarias", en Anuario Mexicano de Derecho Internacional, vol. VII, 2007, pp. 643-673.

SCHALLER, Ch., "Human Security: The Seven Challenges of Operationalizing the Concept", Human Security: 60 minutes to Convince, París, UNESCO, 13 de septiembre de 2005.

SPIERMANN, O., "Humanitarian Intervention as a Necessity and the Threat or Use of Jus Cogens", Nordic Journal of International Law, 2002.

STAHN, C., "Responsability to Protect: Political Rhetoric or Emerging Legal Norm?", 101 AJIL, núm. 1, 2007.

THAKUR, R., The United Nations, Peace and Security. From Collective Security to the Responsibility to Protect, Cambridge, Cambridge University Press, 2006. 